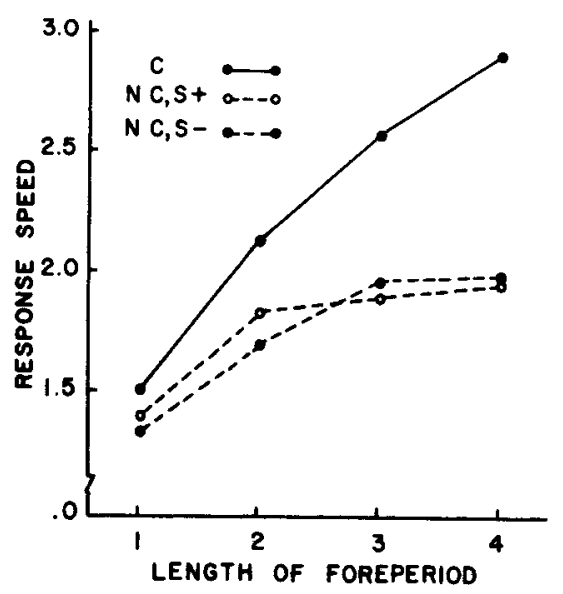

Fig. 1. Mean response speed in the C, NC with $\mathbf{S}+$, and $\mathrm{NC}$ with $\mathrm{S}-$ conditions during test trials with 1-, 2-, 3-, and 4-sec foreperiods.

2- to the 3-sec and from the 3- to the 4-sec foreperiods were not significant. These findings indicate, then, that the differences in the relative speed of the competing responses were nonsignificant during test trials with the four foreperiods, and that, as expected, the absolute speeds of the competing responses increased as a function of the length of the foreperiod.

Further analysis of the simple effects indicated that the speed of the responses in the $C$ condition were significantly $(p<.01)$ faster than the speed of the responses in both of the NC conditions during test trials with 2-, 3-, and 4-sec foreperiods, but not during test trials with a $1-\mathrm{sec}$ foreperiod; and also, that the response speeds in the $\mathrm{C}$ condition increased significantly $(p<.01)$ from the 1- to the $2-\mathrm{sec}$, from the 2 - to the $3-\mathrm{sec}$, and from the 3 - to the $4-\mathrm{sec}$ foreperiods.

Thus, the results show that the speed of the response occurring in a conflict situation is faster than the speed of either of the competing responses in nonconflict situations, and consequently, agree with previous investigations demonstrating the effects of conflict-produced drive. In addition, the results indicate, as Brown \& Farber (1951) have proposed, that the speed of the response occurring in a conflict situation is a function of the absolute strengths of the competing responses. The nature of this function is suggested by the data presented in Fig. 1. That is, Fig. 1 shows that the response speeds in the $\mathrm{C}$ condition and in both of the $\mathrm{NC}$ conditions are negatively accelerated functions of the length of the foreperiods, that the asymptote for the $\mathrm{C}$ condition is higher than the asymptote for the NC conditions, and that the slope for the $\mathrm{C}$ condition is steeper than the slope for the NC conditions. Plotting the relationship between two such negatively accelerated curves results in a positively accelerated curve, and thus suggests that the speed of the response occurring in a conflict situation increases as an exponential function of the absolute strengths of the competing responses.

\section{REFERENCES}

BROWN, J. S. The motivation of behavior. New York: McGraw-Hill, 1961

BROWN, J. S., \& FARBER, I. E. Emotions conceptualized as intervening variables-with suggestions toward a theory of frustration. Psy chological Bulletin, 1951,48, 465-495.

CASTANEDA, A., \& WORELL, L. Differential relation of latency and respons vigor to stimulus similarity in brightness diserimination. Journal of Experimental Psychology, 1961.61, 309-314.

FINGER, I. W. Quantitative studies of "conflik" I. Variations in latency and strength of the rat's response in a discrimination-jumping situation. Journal of Comparative Psy chology, 1941, 31. 97-127.

LINDQUIST, I:. I. Design and analysis of experiments in psychology and education Boston: Hough ton-Mlifflin, 1953.

MILLFR, N. F, Liberalization of basic S-R concepts: Extensions to conflict behavior, motivation and social learning. In $\mathrm{S}$. Koch ( $\mathrm{Fd}$.), Psychology: A study of a science. Vol. 2. New York: McGraw-Hill, 1959.

\title{
The effects of grouping instructions in short-term memory
}

JAMES M. FURUKAWA, The Johns Hopkins University, Baltimore, Md. 21218, MARY M. SUYDAM and STUART MILLER, Towson State College, Towson, Md. 21204

The effects of two levels of short-term memory (STM) and three levels of instructions were investigated in a serial. learning task. High-and low-STM Ss were assigned simple serial-learning instructions, instructions to learn by pairing words, or instructions to learn by quadrupling words. The results from this 2 by 3 , extreme-groups design showed that instructions to pair or quadnuple words significantly facilitated performance $(p<.01)$ and reduced the correlation between STM and learning from $.56(p<.05)$ to $.05 \quad(p>.05)$. The difference between high- and low-STM Ss found in an earlier study was eliminated by providing grouping instructions to the Ss.

Several early Es found that is was possible to improve memory span by either practice or specific training in study techniques, such as association formation and grouping (Gates \& Taylor, 1925; Martin \& Fernberger, 1929; Woodrow, 1927). However, these investigators did not compare the performance of Ss with different memory spans. Furthermore, the effects of grouping instructions, per se, were not determined.

Furukawa and Suydam 2 studied various determinants of the serial-position curve including short-term memory (STM). One factor which may have been responsible for the demonstrated superiority of high- over
low-STM Ss was the tendency of high-STM Ss to group adjacent items of the list into pairs. This result led to the following hypothesis: If low-STM Ss are given specific instructions to form groups of items in a serial-learning task, then their performance should more closely match that of high-STM Ss. To test the hypothesis, the materials and procedures of the Furukawa and Suydam study were used.

\section{SUBJECTS}

The Ss were 42 educational psychology students at Towson State College. Their ages ranged from 18 to 22 years, with approximately equal numbers of male and female Ss.

\section{MATERIALS}

The STM spans of the Ss were determined by the use of 20 two-digit numbers selected from a list of random numbers and 20 adjective-noun word combinations randomly selected from an history text, as shown in Table 1.

A total of $12100 \%$ association-value consonsant-vowel-consonant (CVC) trigrams were selected from Archer's norms (1960) to form a serial list. The trigrams, presented to $S s$ in alphabetical order, were: BAN, COD, DAB, FIN, GAP, HID, JON, KEG, LAD, MUG, NED, and POT.

\section{PROCEDURE}

The items used to determine STM were printed on flash-cards and presented to $S$ s in three educational psychology classes, with the following instructions:

"This is a test of your short-term memory. You will be shown a series of two-digit numbers at the rate of one 
Table 1

Short-Term Memory Test

Two-Digit Numbers Two-Word Combinations

\begin{tabular}{ll}
63 & Excellent device \\
32 & Corporate charter \\
14 & Land grants \\
75 & First person \\
21 & Other families \\
52 & Glass beads \\
73 & Gallant soul \\
87 & Quarter horse \\
26 & Next governor \\
48 & Fascinating subject \\
78 & Thousand years \\
74 & Main reason \\
76 & Alleged voyages \\
28 & Colonial era \\
42 & Trading posts \\
57 & Next spring \\
38 & Best work \\
85 & Famous descendant \\
17 & Ninety sailors \\
13 & Unhappy relation \\
\hline
\end{tabular}

every $2 \mathrm{sec}$. At the completion of the showing, you will be given the signal to 'recall.' At that time, you will be given 2 min to write as many of the numbers as you can remember, in any order that you want. The process will be repeated with two-word adjective-noun combinations. Do you have any questions?"

Scoring was accomplished by giving one point for each two-digit number correctly recalled. A point was scored for each pair of words correctly recalled and one-half point was scored if only one word of a pair was correct. The two scores were summed and divided by 2 . This average became the STM score.

After an interval of 1 week, the serial list was presented on an artboard to each of the three classes. Ss were allowed to study the list for $12 \mathrm{sec}$, with $72 \mathrm{sec}$ for written, serial recall. The general instructions for all classes were as follows:

"You will be shown 12 consonantvowel-consonant (CVC) trigrams for a period of $12 \mathrm{sec}$. At the end of that time, you will be asked to recall as many of them as you can in the exact sequence in which you saw them, i.e., the first one must be written first, the second one next, etc., from top to bottom. You will be given $72 \mathrm{sec}$ in which to do this. Note that the 12 trigrams are in alphabetical order, minus the vowels AEIO since we are only looking at trigrams with a CVC ordering. In other words, the first trigram begins with $B$, the next with $C$, etc. To avoid confusion, I have written the first letters of the trigrams for each of the 12 positions on the sheet of paper provided."

One of the three classes was randomly assigned to each of the instructional conditions-no instructions (0), pairing (2), and quadrupling (4). Ss in Conditions 2 and
4 were given the following grouping instructions, in addition to the general instructions.

"Coding or associating words together can increase your ability to learn things. For example, in the learning task in which you will be engaged, instead of 12 chunks of information or $12 \mathrm{CVC}$ trigrams, it is possible for you to learn the same task better by-[Group 2:] Pairing 1 and 2, 3 and 4 , etc., and thereby reducing the chunk level requirement to only six. For example, if the first word is 'hot,' and the second word is 'dog,' remember the two together as 'hotdog.' [Group 4:] Quadrupling 1, 2, 3, and 4 together, and therby reducing the chunk level requirements to only three. For example, if the first word is 'very,' the second 'hot,' the third 'summer,' and the fourth 'day,' remember the four together as "very hot summer day.",

Under all experimental conditions, a response was scored correct only if the trigram was reproduced accurately and in the proper serial position. However, only the data of high-STM Ss (scores of 10.5 or greater on the STM test) and low-STM Ss (scores of 8.5 or less) were analyzed.Ss were also selected based on matching STM scores so that the three instructional conditions contained seven high- and seven low-STM Ss.

\section{RESULTS AND DISCUSSION}

Mean number of correct responses for each treatment combination are presented in Table 2. Analysis of variance revealed a significant effect for instructions $[F(2,36)=8.62, p<.011$. Scheffé's test for multiple comparisons indicated that both pairing $(\mathrm{p}<.05)$ and quadrupling $(\mathrm{p}<.01)$ were significantly better than no instructions. The facilitating effect of instructions can be accounted for by Miller's (1956) chunking hypothesis. As the $S$ is instructed to form larger units of the material, the absolute number of chunks he must remember decreases. The instructions seem to provide $S$ with a very helpful way of making use of the limited amount of presentation time.

There was also a small but significant difference $[F(1,36)=3.28, p<.10]$ in the performance of the high- and low-STM Ss. Furukawa and Suydam had earlier found a highly significant difference between highand low-STM Ss, under identical conditions for a no-instruction group. The reduced significance level may be partly attributed to the effectiveness of the instructional variable.

Although the STM by Instruction interaction was not significant, Table 2 reveals that the mean difference in performance between high- and low-STM Ss
Table 2

Mean Number of Correct Responses in Serial Learning

\begin{tabular}{lccc}
\hline & \multicolumn{3}{c}{ Type of Instructions } \\
\cline { 2 - 4 } STM & 0 & 2 & 4 \\
\hline High & 4.85 & 6.43 & 6.86 \\
Low & 3.57 & 5.29 & 6.59 \\
\hline
\end{tabular}

was reduced from 1.29 to .27 . In addition, the correlation between STM and number of correct responses in serial learning was significant when Ss were given no instructions $[r(12)=.56, p<.05]$, but was not significant under pairing or quadrupling instructions $[r(12)=.39, .05 ; p>.05]$. It is not surprising to find a significant relationship between memory span and number of correct responses in serial learning, since both tasks are STM tests-S is tested for recall after a single presentation of the material. The correlation, however, breaks down when Ss are given grouping instructions in serial learning.

The correlational results seem to indicate that low-STM Ss benefited more from the grouping instructions than did the high-STM Ss. If instructions affected all Ss in the same way, it would be as if a constant were added to the learning score of each $S$, thus leaving the correlation unchanged. The relationship between STM and learning in the uninstructed condition may then be due to the spontaneous use of organizational strategies by high-STM Ss. Instructions to group, however, cause low-STM Ss to adopt the same learning techniques used by $S s$ with high STM.

Further studies should be conducted to determine whether the effect of grouping instructions holds over time. In addition, the study should be replicated with materials and procedures which have greater generalizability to classroom situations.

\section{REFERENCES}

ARCHER, E. J. Reevaluation of the meaningfulness of all possible CVC trigrams. Psychological Monographs. 1960, 74. No. 497.

GATES, A. I., \& TAYLOR, G. A. An experimental study of the nature of improvement resulting from practice in a mental function. Journal of Educational Psychology, 1925, 16, 583-592.

MARTIN, P. R., \& l:HRNBERGFR, S. W. Improvement in memory span. American Journal of Psychology, 1929, 41.91-94.

MILLER, G. A. The magical number seven, plus or minus two: Some limits on our capacity for processing information. Psychological Review, $1956,63,81-97$.

WOODROW, H. The effect of type of training upon transference. Journal of Educational Psychology, 1927. 18, 159-172.

\section{NOTES}

1. Now at Towson State College, Towson, Maryland 21204

2. I urukawa, J. M.. \& Suydam, M. M. Position confusion. meaningfulness, and short-term memory effects on the serial-position curve. Unpublished manuscript. 